\title{
Research on Input-output Efficiency of China's Postal Industry Based on Super-SBM Model
}

\author{
Chen Hongping ${ }^{1, \text { a, }}$, Hou Jie ${ }^{1, b}$, Wang Fen ${ }^{2, ~ c ~}$ \\ ${ }^{1}$ School of Economics and Management, Xi'an University of Posts and Telecommunications, Xi'an, \\ Shaanxi 710061, China \\ ${ }^{2}$ School of Economics and Management, Zhejiang Ocean University, Zhoushan, Zhejiang 316022, \\ China \\ achenhp@xupt.edu.cn, ${ }^{b}$ hjhaaoj@163.com, ${ }^{c}$ worphan77@163.com
}

Keywords: postal industry; Super-SBM model; input-output efficiency

Abstract: 2016, as the first year of the 13th Five-Year Plan for China's postal industry, puts forward higher requirements for the deepening reform of the industry. This paper uses the Super-SBM model to empirically analyze the input-output efficiency of the postal industry in 31 provinces of China. The results show that the overall efficiency of China's postal industry is low, and the difference in the efficiency of the postal industry in each province in 2011 and 2016 is compared. It is concluded that the overall efficiency of input and output of China's postal industry in 2016 has declined slightly compared with that of 2011. The gap between regions is significant, and the input and output efficiency is highest in the eastern region, followed by the central and western regions, and the lowest in the northeast region. In some provinces, the postal industry has problems of excessive investment and insufficient output, mainly due to the inefficient use of resources.

\section{Introduction}

At the end of 2016, the State Post Bureau and the National Development and Reform Commission and the Ministry of Transport jointly promulgated the "13th Five-Year Plan for the Development of the Postal Industry", indicating that China attaches importance to the deepening reform, transformation and upgrading of the postal industry, and the planning proposes a certain degree of acceleration. The pace of reform of the industry has provided strategic guidance for the implementation of the modern postal industry goals that are compatible with the well-off society. As an important social public utility of the country, the postal industry is a modern leading industry that promotes the transformation of circulation mode and promotes consumption upgrading. It plays the role of basic, service and pilot in the development of national economy. As a key industry in the modern service industry, it has established an information network system that integrates information flow, real logistics and capital flow, and has played a role in reducing circulation costs, supporting e-commerce, serving production and life, and expanding employment channels. The positive role has effectively promoted the steady and rapid development of China's national economy.

In recent years, with the continuous improvement of the construction of the legal system of the 
postal industry and the formulation of regulatory policies, the operational performance of the industry has gradually improved; according to the statistical information publicly released by the State Post Bureau [1], The total volume of the postal industry in the country increased from 127.37 billion yuan in 2007 to 976.37 billion yuan in 2017, and the proportion of the industry-wide business income (excluding the direct operating income of the Postal Savings Bank) to the gross national income increased from $0.33 \%$ in 2007 to $0.72 \%$ in 2016; The industry has developed rapidly, but the driving force for economic growth is still insufficient, and it has not shown good economic transmission. As of 2016, the number of postal business outlets increased by $14.88 \%$ year-on-year. The average service area and service population of each business outlet decreased by $12.95 \%$ and $12.17 \%$ year-on-year; indicating that the layout of business outlets is unreasonable, and the function of postal universal service failed. Maximize the benefits and waste the postal resources. Therefore, whether the scale of resource investment is reasonable has always been the primary problem facing the development of the industry. It not only directly determines the general service quality of the postal industry, but also will be the cornerstone of the future transformation and upgrading of the industry.

\section{Summary of research status at home and abroad}

At present, the academic research on the postal industry is mostly biased towards qualitative analysis, and the research on the evaluation of input and output efficiency of the postal industry is still lacking. Yang Baolin and Wang Junsheng (2012) used the MCMC method to evaluate the technical efficiency of the postal industry in the eastern, central and western regions of China from 2001 to 2010, and concluded that the technical efficiency of the eastern, central and western regions is not high, which is the highest in the east, the second in the middle, and the lowest in the west [2]. Li Xiaochao et al. (2016) used Zhejiang Province as an example to analyze the six characteristics of the postal industry and its related industry dynamics based on industrial relevance and ripple theory [3]. Since the Data Envelopment Analysis Method (DEA) has been widely used by domestic scholars to evaluate the efficiency of multi-input and multi-output postal industries, for example, Jin Ruijie (2001) used the traditional DEA method to measure the input efficiency of postal enterprises in 31 provinces and cities in China. The results show that the comprehensive efficiency of China's postal enterprises is low [4]. Huang Yuansheng et al. (2013) conducted research on the postal industry as a separate industry, and used the DEA model to construct an index evaluation system for evaluating the operational efficiency of the industry, and gave conclusion analysis and policy recommendations [5]. Wang Ling et al. (2016) used the two-stage DEA model to conduct empirical research on the operational efficiency, market efficiency and overall operational efficiency of China's postal industry from 2007 to 2012, respectively, from the operational stage and the marketization stage, and it is concluded that the overall operation efficiency of China's postal industry is low [6]. Foreign scholars have in-depth discussion on the efficiency mechanism of the postal industry from different angles in view of postal operational performance problems. For example, Nikola Knežević et al. (2011) proposed a two-stage human resource management model, and combined with regression analysis and DEA method to empirically study the organizational efficiency of the Yugoslav postal system [7]. Kiril Tochkov et al. (2015) used non-parametric methods to measure the relevant technologies and cost efficiencies of postal operators in Central and Eastern Europe based on quantity and quality output indicators. The results showed that inefficiencies varied between $20 \%$ and $30 \%$, and competition increased. Institutional reform, simplified customs procedures, and population density are the main reasons for efficiency improvement [8]. Florian Ploeckl (2016) used the regional productivity of the Ministry of Posts and Telecommunications and the postal service of the German Empire to use the data envelopment 
analysis efficiency score to derive the relative productivity of the postal, telegraph and telephone departments from 1891 to 1908. The results showed a fully stable postal service. The system has large productivity differences between postal areas, and service expansion offsets the increase in mail service technology productivity [9]. Predrag Ralević et al. (2016) analyzed the complete postal network of 1194 postal offices in Serbia, and used data envelopment analysis to measure the cost efficiency of each department. It was found that at least 794 branches can increase efficiency through resource redistribution. [10].

Therefore, based on the "13th Five-Year Plan", this paper compares the input and output efficiency of the postal industry in 31 provinces, municipalities and autonomous regions in China in 2011 and 2016 based on the Super-SBM model, breaking the traditional DEA. The method studies the pattern of industry efficiency and improves the shortcomings of the traditional DEA type. By comparing the difference in input and output efficiency of the postal industry in each region over time, we can fully understand the development status of the industry at this stage, and then lay a reference standard for the supply-side structural reform of the postal industry.

\section{Super-SBM model construction and evaluation index selection}

\subsection{Introduction of Super-SBM model}

The Data Envelopment Analysis Method (DEA) was first proposed by A. Charnes and WW Cooper et al. in 1978, using a mathematical programming model for each decision making unit (DMU) with multiple inputs and multiple outputs. A relative effectiveness evaluation is performed, and whether the DMU is a valid non-parametric statistical method for DEA is inferred based on whether the data observed by each DMU is located on the production frontier [11].

Because the traditional DEA model is based on relative efficiency, there are defects such as angle and radiality in the efficiency evaluation; Kaoru Tone developed the SBM model based on the DEA model, which not only solves the problem by introducing the slack variable into the objective function. The slack problem of input and output, and also to some extent, reduces the deviation of the efficiency evaluation results, making the efficiency evaluation value more accurate [12]. Kaoru Tone proposed the Super-SBM model in 2002, which not only can obtain a complete ranking of effective decision-making units, but also eliminates the slack problem, further optimizes the shortcomings of the SBM model [13], making the model show a more accurate metric.

The basic principle of the Super-SBM model is to assume that there are $n$ decision units, each of which uses $m$ inputs $i(i=1,2, \cdots, m)$ to produce $s$ output $r(r=1,2, \cdots, s)$. If the decision unit to be evaluated is recorded as $\operatorname{DMU}_{\mathrm{j}}(j=1,2, \cdots, n), x_{i j}$ represents the i-th input of the $\mathrm{j}$-th DMU, and $y_{r j}$ represents the r-th output of the j-th DMU; this paper intends to construct a Super-SBM model with variable scale returns, and its specific expression is as follows: 


$$
\begin{aligned}
& \theta^{*}=\min \theta=\frac{\frac{1}{m} \sum_{i=1}^{m} \bar{x}_{i} / x_{i 0}}{\frac{1}{s} \sum_{r=1}^{s} \bar{y}_{r} / y_{r 0}} \\
& \text { s.t. }\left\{\begin{array}{l}
\bar{x} \geq \sum_{j=1, \neq 0}^{n} \lambda_{j} x_{j} \\
\bar{y} \leq \sum_{j=1, \neq 0}^{n} \lambda_{j} y_{j} \\
\bar{x} \geq x_{0} \text { and } \bar{y} \leq y_{0} \\
\sum_{j=1, \neq 0}^{n} \lambda_{j}=1 \\
\bar{y} \geq 0, \lambda \geq 0
\end{array}\right.
\end{aligned}
$$

In formula (1), $\theta^{*}$ is the super efficiency score of the decision unit, $\lambda_{j}$ is the weight vector of the $j$-th DMU, and the slack variables of input and output are represented by $s^{-}$and $s^{+}$, respectively.

\subsection{Selection of evaluation indicators and data sources}

The postal industry is closely related to the national economy and the people's livelihood. As an important part of the national economy and social development, it is an indispensable service department in social production activities. As a basic human right, postal services can be divided into three major sectors: universal service, special service and commercial service. This paper constructs the evaluation index system of the postal industry from the perspective of input and output, and selects the number of postal employees, the financial expenditure of transportation, the number of postal business outlets, the total length of postal routes, and the delivery route based on human, financial and material aspects. The total length is used as an input indicator; while the postal industry output is mainly divided into direct output and indirect output. The direct output indicator selects the total amount of postal services, the amount of parcels, and the number of express items to reflect the operating performance of the industry. The number of service outlets in a business outlet reflects the fairness, openness and impartiality of the postal universal service function. The above selected indicators meet the number of decision-making units at least three times the sum of the input-output indicators. The indicator data are derived from the 2012 China Statistical Yearbook and the 2017 China Statistical Yearbook, ensure the authenticity, objectivity and consistency of the data source.

\section{Empirical results and analysis}

The Super-SBM model is used to analyze the postal industry from the perspective of input and output. DEA-SOLVER Pro5.0 software is used to measure the data of each evaluation index, and finally, the comprehensive efficiency, pure technical efficiency and scale efficiency of the postal industry in 31 provinces, municipalities and autonomous regions in China were obtained in 2011 
and 2016. The Mydea software was used as a supplement to analyze the scale income changes of the postal industries in each province. The results are shown in Table 1.

Table 1. Evaluation results of input and output efficiency of postal industry in 31 provinces in China in 2011 and 2016.

\begin{tabular}{|c|c|c|c|c|c|c|c|c|}
\hline \multirow{2}{*}{ Area } & \multicolumn{4}{|c|}{2016} & \multicolumn{4}{|c|}{2011} \\
\hline & $\mathrm{TE}$ & PTE & $\mathrm{SE}$ & RTS & $\mathrm{TE}$ & PTE & $\mathrm{SE}$ & RTS \\
\hline Beijing & 1.310 & 1.366 & 0.959 & drs & 1.186 & 1.190 & 0.996 & irs \\
\hline Tianjin & 1.091 & 1.153 & 0.946 & irs & 1.256 & 1.273 & 0.986 & irs \\
\hline Hebei & 1.064 & 1.073 & 0.991 & drs & 1.260 & 1.306 & 0.965 & drs \\
\hline Shanxi & 0.269 & 0.305 & 0.880 & irs & 0.293 & 0.296 & 0.989 & irs \\
\hline $\begin{array}{c}\text { Inner } \\
\text { Mongolia }\end{array}$ & 0.080 & 0.086 & 0.925 & irs & 0.224 & 0.234 & 0.955 & irs \\
\hline Liaoning & 0.373 & 0.377 & 0.988 & irs & 0.477 & 0.482 & 0.989 & irs \\
\hline Jilin & 0.236 & 0.250 & 0.941 & irs & 0.379 & 0.397 & 0.956 & irs \\
\hline Heilongjiang & 0.255 & 0.261 & 0.978 & irs & 0.332 & 0.341 & 0.974 & irs \\
\hline Shanghai & 1.296 & 1.333 & 0.972 & irs & 1.250 & 1.255 & 0.995 & irs \\
\hline Jiang Su & 1.002 & 1.006 & 0.995 & drs & 1.049 & 1.050 & 0.999 & drs \\
\hline Zhejiang & 1.219 & 1.223 & 0.996 & irs & 1.129 & 1.145 & 0.985 & drs \\
\hline Anhui & 1.142 & 1.154 & 0.989 & irs & 0.649 & 0.667 & 0.972 & irs \\
\hline Fujian & 0.473 & 0.474 & 0.998 & irs & 0.590 & 0.602 & 0.979 & drs \\
\hline Jiangxi & 0.475 & 0.534 & 0.889 & irs & 0.424 & 0.436 & 0.973 & irs \\
\hline Shandong & 0.460 & 0.461 & 0.998 & drs & 0.625 & 1.011 & 0.618 & drs \\
\hline Henan & 1.007 & 1.020 & 0.987 & drs & 0.578 & 0.584 & 0.989 & drs \\
\hline Hubei & 0.301 & 0.304 & 0.989 & irs & 0.469 & 0.475 & 0.987 & drs \\
\hline Hunan & 0.463 & 0.484 & 0.956 & irs & 0.462 & 0.465 & 0.992 & irs \\
\hline Guangdong & 1.166 & 1.294 & 0.901 & drs & 1.022 & 1.416 & 0.721 & drs \\
\hline Guangxi & 0.217 & 0.220 & 0.986 & irs & 0.306 & 0.308 & 0.991 & drs \\
\hline Hainan & 0.173 & 0.261 & 0.665 & irs & 0.479 & 0.513 & 0.934 & irs \\
\hline Chongqing & 0.271 & 0.282 & 0.963 & irs & 0.344 & 0.345 & 0.994 & irs \\
\hline Sichuan & 0.245 & 0.246 & 0.996 & drs & 0.365 & 0.409 & 0.893 & drs \\
\hline Guizhou & 0.138 & 0.155 & 0.891 & irs & 0.186 & 0.192 & 0.967 & irs \\
\hline Yunnan & 0.148 & 0.153 & 0.967 & irs & 0.258 & 0.262 & 0.984 & irs \\
\hline Xizang & 0.060 & 0.999 & 0.060 & irs & 1.022 & 1.428 & 0.716 & irs \\
\hline Shaanxi & 0.277 & 0.283 & 0.978 & irs & 0.331 & 0.332 & 0.998 & irs \\
\hline Gansu & 1.019 & 1.033 & 0.986 & drs & 0.196 & 0.208 & 0.943 & irs \\
\hline Qinghai & 1.226 & 1.355 & 0.904 & irs & 1.218 & 1.240 & 0.982 & irs \\
\hline Ningxia & 0.521 & 1.688 & 0.308 & irs & 1.089 & 1.163 & 0.936 & irs \\
\hline Xinjiang & 1.067 & 1.072 & 0.995 & irs & 0.226 & 0.278 & 0.815 & drs \\
\hline National & 0.614 & 0.707 & 0.902 & & 0.635 & 0.687 & 0.941 & \\
\hline
\end{tabular}

Note: (1)TE, PTE, and SE represent technical efficiency, pure technical efficiency, and scale efficiency, respectively; (2)RTS represents scale returns, and irs and drs represent incremental and decreasing scale returns, respectively. 


\subsection{The overall situation of China's postal industry input-output efficiency}

1) From the perspective of overall efficiency, the overall efficiency of China's postal industry is low, and there are large differences between different provinces. In 2016, the average efficiency of input and output efficiency of China's postal industry was 0.615 , which was a small decrease compared with 2011. The main reason was the rapid rise of private and foreign express delivery companies. The postal parcel business was gradually replaced by the emerging express delivery market. From 68.83 million in 2011 to 29.94 million in 2016, it fell by 59.41\%, which has greatly hindered the sustainable development of the postal industry, and more than half of the provinces fell by more than $60 \%$. In addition, in 2016, the input and output efficiency of the postal industry in 12 provinces reached an effective frontier, with 19 ineffective provinces accounting for $61.29 \%$ of the country, and 10 provinces with effective frontiers in 2011 and 21 ineffective provinces. , accounting for $67.74 \%$ of the country; the intersection of the effective provinces in the two years is Beijing, Tianjin, Hebei, Shanghai, Jiangsu, Zhejiang, Guangdong, Qinghai, and the efficiency of the input and output efficiency of the inefficient provinces is far away. Under the effective border, it indicates that these provinces have a low level of production technology that translates into a postal product or service with a given resource input.

2) The overall efficiency depends on pure technical efficiency and scale efficiency. Therefore, it is necessary to further judge the main reasons for the inefficiency of the postal industry in the ineffective provinces from the perspectives of pure technical efficiency and scale efficiency. The scale efficiency values of postal services in 11 provinces of Inner Mongolia, Liaoning, Jilin, Heilongjiang, Fujian, Hubei, Hunan, Guangxi, Chongqing, Yunnan, and Shaanxi were all in the range of $(0.9,1)$ in 2011 and 2016, relatively close to the optimal scale, but the pure technical efficiency is far lower than the national average, indicating that the inefficiency of the postal industry in these provinces is mainly affected by the pure technical efficiency, that is, the postal resource utilization technology is low, and the scientific and technological achievements are not capable of transforming; The scale efficiency values of the postal services in the four provinces of Shanxi, Jiangxi, Hainan and Guizhou were closer to the optimal scale in 2011, but were lower than 0.9 in 2016, and the pure technical efficiency value was far below the national average. It shows that the development of the postal industry in these four provinces has experienced two inefficient stages. The resource utilization technology has been running through two periods. The pure technical inefficiency in the previous stage has gradually led to the relatively inefficient technology and scale in the latter stage; the postal industry in Tibet and Ningxia has developed from the effective state in 2011 to the ineffective state in 2016, but the pure technical efficiency values are all greater than 1 . There is no problem that resources are not used most effectively, so the postal industries in these two provinces are In the process of development, it has gradually fallen into the trap of imbalance in scale structure; The postal industries in the four provinces of Anhui, Henan, Gansu and Xinjiang have evolved from the ineffective state in 2011 to the effective state in 2016, indicating that the operation of the postal industry in these four provinces has gradually returned to the right track, out of the scale trap, and resource utilization technology. Continuous improving; Taking Xinjiang as an example, the number of postal employees, the total length of postal routes and the total length of delivery lines decreased by $15.09 \%, 3.04 \%$, and $65.19 \%$ respectively compared with 2011, but the total amount of postal services and express delivery business have been greatly improved, respectively increased by $90.29 \%$, 351.23\%.

3) Analysis of the scale of operation of the postal industry in each province from the change of scale returns, which is conducive to managers to appropriately adjust the scale structure. In the two provinces of Beijing and Gansu, the scale income of the postal industry will increase first and then decrease, and in this process, it will enter a saturated state (peak top), that is, the optimal production 
scale, and the scale of the enterprise will reach the maximum value; It shows that the postal industry in these two provinces is currently at the end of the economic cycle. At this stage, the scale of operations is too large and should be appropriately reduced. According to the theory of cyclical economic fluctuations, the industry will gradually enter a new stage of increasing scale; The postal industries in 18 provinces including Tianjin, Shanxi, Inner Mongolia, Liaoning, Jilin, Heilongjiang, Shanghai, Anhui, Jiangxi, Hunan, Hainan, Chongqing, Guizhou, Yunnan, Tibet, Shaanxi, Qinghai and Ningxia are in the stage of increasing scale returns, regardless of experience. After a complete economic cycle, it will enter a new incremental phase, or it will continue to increase in the long-term. Continued increase in investment will stimulate more output. Therefore, it is necessary to appropriately expand the scale of operation of the industry and strengthen the degree of specialization of the internal governance structure of the industry. In turn, the overall efficiency of the postal industry's input and output will be improved, laying a good material foundation for the industry's subsequent optimal production scale; the postal industries in the six provinces of Hebei, Jiangsu, Shandong, Henan, Guangdong and Sichuan are in the stage of diminishing returns to scale. Whether it is in the diminishing phase of an economic cycle or in the diminishing phase for a long time, continuing to increase investment will lower economic output; It shows that the current operation scale is too large, which not only reduces the coordination ability of all aspects of the business, but also increases the internal management costs. Therefore, the scale of the postal industry should be appropriately reduced, and the limited resources should be fully utilized to make the scale structure of the industry more reasonable; In the five provinces of Zhejiang, Fujian, Hubei, Guangxi, and Xinjiang, the scale income of the postal industry will decrease first and then increase, and in this process, it will enter a vacant state (the bottom), that is, the worst production scale, and the scale of the enterprise will reach the minimum, but It also shows that the postal industry in these five provinces has experienced a cycle of economic cycles. The percentage of increase in output at this stage is greater than the percentage increase in input. The scale of operation of the industry should be appropriately expanded to achieve the optimal production scale.

\subsection{Analysis of the comparison of input and output efficiency of postal industry in various regions}

In order to make the policy formulation more in line with the actual needs and needs of the economic development of the industry, the country is divided into four economic regions to further compare the development differences of the postal industry in various regions. It can be seen from Figure 1 that the input-output efficiency of the postal industry varies greatly among regions, and the overall efficiency of the eastern region is much higher than the national average, indicating that the industrial structure of the postal industry in the region is reasonable and a better resource allocation is achieved. In the central and western regions, the gap between the development of the postal industry in the eastern and western regions is gradually narrowing compared with that in 2011. It is urgent to develop a rational industrial policy for the postal industry in the central and western regions to enhance the internal development of the region; the lowest efficiency value is far lower than the national average. The reason is that the economic development in the northeast region is relatively backward, resulting in the lack of infrastructure in the postal industry and serious shortage of output. In 2016, the postal business outlets in the northeast region, the total length of the postal route, and the total length of delivery lines accounted for $6.64 \%, 8.46 \%$ and $8.86 \%$ of the national

total, respectively. The number of parcels, express delivery and service population accounted for $8.41 \%, 2.41 \%$ and $9.24 \%$ of the national total, and the total postal service accounted for only $2.92 \%$ of the national total.

By exploring the root causes of the backward development of the postal industry in the central, 
western and northeastern regions, it is easy for the various sectors of the industry to prescribe the right medicines, thereby narrowing the development gap of the postal industry in various regions. The scale efficiency values of the postal industry in the central and northeastern regions are all within the range of $(0.9,1)$, which is close to the optimal scale, but the pure technical efficiency is far lower than the national average and the technology is low. Therefore, we should pay attention to the new technology. The introduction and research and development, adopting active technology introduction policies, and then improving the utilization technology of postal resources, so that limited resources can be utilized most efficiently; in 2016, the scale efficiency of the postal industry in the western region was less than 0.9, compared with 2011. The decline, pure technology inefficiency runs through the two periods before and after, and the industrial concentration in the later period is low, and there is no scale effect. Therefore, it is necessary to take into account the introduction and research of new technologies and the optimization and adjustment of the scale structure, and formulate relevant technology introduction policies and economies of scale. The policy will further improve the overall input and output efficiency of the postal industry at this stage.

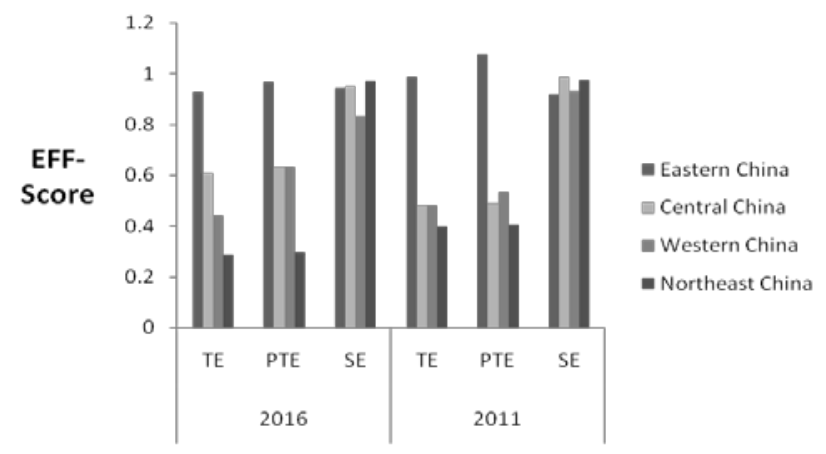

Figure 1. Comparison of input and output efficiency of postal industry in various regions of China in 2011 and 2016.

\subsection{Analysis of the reasons for the inefficiency of input and output in the postal industry in each province}

The projection analysis of the DEA method is based on the optimal production frontier to judge the degree of deviation between the actual value and the target value of each decision unit input and output, so as to clearly adjust the slack of input and output. Through the projection analysis of the input and output of the postal industry in China's ineffective provinces in 2016, it helps the postal industries in each province to adjust the inputs and outputs appropriately in light of the actual situation at the current stage to achieve the matching of inputs and outputs. See Table 2.

1) From the perspective of investment, the investment in postal business outlets, employees and delivery lines is relatively large, and the postal resources are seriously wasted, which is an important factor leading to the low efficiency of input and output in the postal industry; The largest investment redundancy rate is the delivery line, and an average of $50.28 \%$ of the resources are not fully utilized. The reason is that with the rise of e-commerce, the rapid development of the emerging express market has been greatly stimulated. The traditional postal delivery line is difficult to meet the timeliness and security requirements of express delivery. On the other hand, the overall construction of China's postal roads is relatively reasonable, and the input redundancy rate is $4.94 \%$, which basically realizes the effective allocation of postal routes. As a guarantee for the connection of postal communication networks and postal transportation, the postal universal service has been effectively implemented to all levels of provinces, cities and towns, and the proportion of postal administrative villages has reached $99.40 \%$. 
2) From the perspective of output, the output of the two output indicators, the number of express delivery and the total volume of postal services, is seriously insufficient. The reason is that the market impact of some private and foreign express delivery companies has greatly weakened the competitiveness of the postal express market. The growth rate of express delivery decreased from $57.04 \%$ in 2011 to $51.37 \%$ in 2016. The growth rate of express delivery business is relatively slow, and there is still much room for growth in the future; Secondly, the national package shortage rate

Table 2. Projection analysis results of postal industry inputs and outputs in each invalid province in 2016.

\begin{tabular}{|c|c|c|c|c|c|c|c|c|c|c|}
\hline & \multirow{2}{*}{ area } & \multicolumn{5}{|c|}{ Input redundancy rate } & \multicolumn{4}{|c|}{ Underproduction rate } \\
\hline & & $\mathrm{S}^{-}(1)$ & $\mathrm{S}^{-}(2)$ & $\mathrm{S}^{-}(3)$ & $\mathrm{S}^{-}(4)$ & $\mathrm{S}^{-}(5)$ & $\mathrm{S}^{+}(1)$ & $\mathrm{S}^{+}(2)$ & $\mathrm{S}^{+}(3)$ & $\mathrm{S}^{+}(4)$ \\
\hline \multirow{4}{*}{ 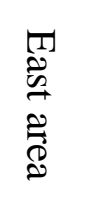 } & Fujian & $40.06 \%$ & $28.07 \%$ & $39.45 \%$ & $47.58 \%$ & $0.00 \%$ & $0.00 \%$ & $141.00 \%$ & $7.16 \%$ & $33.86 \%$ \\
\hline & Shandong & $0.99 \%$ & $0.00 \%$ & $21.73 \%$ & & $0.00 \%$ & $123.92 \%$ & $0.00 \%$ & $166.37 \%$ & $0.00 \%$ \\
\hline & Hainan & & $0.00 \%$ & & & $0.00 \%$ & $537.88 \%$ & & $941.55 \%$ & $0.00 \%$ \\
\hline & average & $25.45 \%$ & $9.36 \%$ & 30.7 & $40.70 \%$ & $0.00 \%$ & $220.60 \%$ & $93.38 \%$ & $371.69 \%$ & $11.29 \%$ \\
\hline \multirow{5}{*}{ 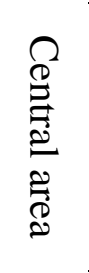 } & Sha & $53.58 \%$ & $0.00 \%$ & 47.1 & $2.04 \%$ & $2.07 \%$ & $248.37 \%$ & $0.00 \%$ & $347.07 \%$ & $0.00 \%$ \\
\hline & Jian & $9.20 \%$ & $0.00 \%$ & 62.3 & $67.27 \%$ & $24.28 \%$ & $15.58 \%$ & $11.71 \%$ & $38.16 \%$ & $0.00 \%$ \\
\hline & Hubei & $54.89 \%$ & $0.00 \%$ & 59. & $69.90^{\circ}$ & 20.5 & $96.99 \%$ & $160.64 \%$ & $125.33 \%$ & $0.00 \%$ \\
\hline & Hunan & $66.93 \%$ & $0.00 \%$ & 72.7 & $77.52 \%$ & 37. & $0.00 \%$ & $0.00 \%$ & $23.12 \%$ & $0.00 \%$ \\
\hline & average va & $61.15 \%$ & $0.00 \%$ & 60. & $69.18 \%$ & $1 \%$ & $90.24 \%$ & $43.09 \%$ & $133.42 \%$ & $0.00 \%$ \\
\hline \multirow{10}{*}{$\begin{array}{l}\sum_{0} \\
0 \\
0 \\
0 \\
0 \\
0 \\
0 \\
0 \\
0\end{array}$} & Inner Mo & $0.00 \%$ & & & $37.85 \%$ & & 999.90\% & & $999.90 \%$ & $0.00 \%$ \\
\hline & Guar & $33.88 \%$ & $0.00 \%$ & 26. & $33.30 \%$ & $0.00 \%$ & $454.17 \%$ & $0.00 \%$ & $639.80 \%$ & $0.00 \%$ \\
\hline & Chong & $25.29 \%$ & $0.00 \%$ & 47. & $27.66 \%$ & $9.87 \%$ & $214.63 \%$ & $227.12 \%$ & $303.63 \%$ & $0.00 \%$ \\
\hline & $\mathrm{S}$ & $47.99 \%$ & 0.00 & 54. & $50.80 \%$ & 17. & $215.09 \%$ & & $.76 \%$ & $0.00 \%$ \\
\hline & Guizhou & $59.32 \%$ & $0.00 \%$ & $32.13 \%$ & $54.21 \%$ & $8 \%$ & $267.06 \%$ & $616.29 \%$ & $537.97 \%$ & $0.00 \%$ \\
\hline & Yunna & $32.48 \%$ & 20. & 0.0 & $55.24 \%$ & & $.50 \%$ & $0.00 \%$ & $.25 \%$ & $0.00 \%$ \\
\hline & & $37.72 \%$ & 24.8 & $0.00 \%$ & $83.09 \%$ & 71. & $999.90 \%$ & $0.00 \%$ & $999.90 \%$ & $0.00 \%$ \\
\hline & Shaanxi & $29.54 \%$ & $0.00 \%$ & $49.39 \%$ & $44.89 \%$ & $0.00 \%$ & $299.76 \%$ & $18.42 \%$ & $367.69 \%$ & $0.00 \%$ \\
\hline & Ning & $53.64 \%$ & 0.00 & 25.7 & $6.42 \%$ & $0.00 \%$ & $28.58 \%$ & $21.90 \%$ & $185.25 \%$ & $0.00 \%$ \\
\hline & averag & $35.54 \%$ & $5.61 \%$ & 28.9 & $43.72 \%$ & $23.90 \%$ & $453.18 \%$ & $130.80 \%$ & $571.13 \%$ & $0.00 \%$ \\
\hline \multirow{4}{*}{ 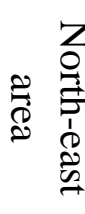 } & Liaoning & $33.97 \%$ & $15.40 \%$ & $0.00 \%$ & $58.73 \%$ & $0.00 \%$ & $188.76 \%$ & $0.00 \%$ & $251.66 \%$ & $0.00 \%$ \\
\hline & Jilin & $22.73 \%$ & $0.00 \%$ & $37.87 \%$ & $51.88 \%$ & $0.00 \%$ & $348.86 \%$ & $0.00 \%$ & $564.07 \%$ & $0.00 \%$ \\
\hline & Heilongjiang & $19.57 \%$ & $0.00 \%$ & $49.63 \%$ & $52.37 \%$ & $0.00 \%$ & $313.20 \%$ & $0.00 \%$ & $470.12 \%$ & $0.00 \%$ \\
\hline & average value & $25.42 \%$ & $5.13 \%$ & $29.17 \%$ & $54.33 \%$ & $0.00 \%$ & $283.61 \%$ & $0.00 \%$ & $428.62 \%$ & $0.00 \%$ \\
\hline $\mathrm{Na}$ & ational average & $37.74 \%$ & $4.94 \%$ & $35.92 \%$ & $50.28 \%$ & $15.77 \%$ & $313.27 \%$ & $85.77 \%$ & $424.99 \%$ & $1.78 \%$ \\
\hline
\end{tabular}

Note: (1) S-(1)-S-(5) represent the postal business outlets, the total length of postal routes, the number of employees, the total length of delivery routes, and the investment redundancy rate of transportation finance, respectively; (2) $\mathrm{S}+(1)-\mathrm{S}+$ (4) Representing the insufficient output rate of the total amount of postal services, the amount of parcels, the number of courier items, and the average number of service persons per business outlet. averaged $85.77 \%$, which also had a greater impact on postal input and output efficiency; On average, the output under-service rate of each business outlet has the lowest output rate of $1.78 \%$, which generally satisfies the public's postal demand, and also reflects the public's high satisfaction with the postal universal service.

3) Each region has its own advantages and disadvantages in the allocation of postal resources. The postal industry in the eastern region has basically realized the effective allocation of delivery 
routes and fiscal expenditures. The shortcoming is that the output efficiency of the service population is low; The postal business outlets, practitioners and delivery lines in the central region have the highest redundancy rate, but the best in the total amount of postal services and the effective output of the service population; The western region has effectively allocated human resources, but the output of express delivery business is seriously insufficient; The northeast region has the best control over postal business outlets and fiscal expenditures, and the output of parcels and service population has been effective.

4) If the postal industries in these ineffective provinces want to be effective, they should be adjusted according to the improvement results in Table 2, respectively reducing the corresponding redundancy rate in the input items and increasing the corresponding deficiency rate in the output items; Taking Shaanxi as an example, the postal industry has three problems of excessive investment and three insufficient output. The postal business network needs to be reduced by $29.54 \%$, the number of employees needs to be reduced by $49.39 \%$, and the delivery line needs to be reduced by $44.89 \%$. The increase is $299.76 \%$, the parcel delivery volume needs to increase by $18.42 \%$ and the number of express delivery needs to increase by $367.69 \%$.

\section{Conclusion}

This paper uses the Super-SBM model to empirically analyze the development status of the postal industry's "13th Five-Year Plan" in 31 provinces, municipalities and autonomous regions in China in 2011 and 2016, and based on the above empirical results, the following conclusions are drawn:

(1) In 2016, the overall input-output efficiency of China's postal industry decreased slightly compared with 2011, and the difference in space and time was obvious. There are 8 valid provinces intersecting in two years, and 17 ineffective provinces. Among them, 2 provinces have effectively degraded from 2011 and became invalid in 2016, and 4 provinces have progressed from 2011 to 2016. The reason for the low efficiency of the postal industry input and output in the provinces is that the pure technical efficiency is low, that is, the postal resource utilization technology is not high, the technology conversion rate is low, and the technology cannot be digested and absorbed after the introduction; secondly, the scale efficiency is low. That is, the scale structure is unbalanced, too blindly expanding the scale of the industry operation, and restricting its operational ability. Therefore, we should actively strengthen the independent innovation capability of the postal industry, optimize the scale structure, and focus on improving soft power, supplemented by hardware investment.

(2) There are significant differences in the changes in scale returns of different provinces, reflecting the fact that the postal industries in each province are at different stages of the economic cycle. In the two provinces, the scale of the postal industry has increased and then decreased. It is currently at the end of the economic cycle. In this process, the optimal production scale has been completed. At this stage, only the scale of operation of the industry needs to be appropriately reduced. All 18 provinces are in the stage of increasing scale returns, which is at the beginning of a certain economic cycle. Continued increase in investment will stimulate more output, and the scale of operation of the industry needs to be further expanded. Six provinces are in the stage of diminishing returns to scale. At the end of a certain economic cycle, increasing investment will reduce output, and the current scale of operations of the industry should be appropriately reduced. The scale of the postal industry in five provinces will decrease first and then increase, and a cycle of economic cycles has ended. At the beginning of the new economic cycle, the development potential is huge, and it is necessary to appropriately expand the scale of operation of the industry in order to achieve the best production scale. 
(3) The regional characteristics of the input-output efficiency of China's postal industry show a trend of decreasing from east to west. The overall efficiency value of the eastern region is the highest, far higher than the national average. The reason is that the eastern region is more complete in infrastructure construction due to its superior geographical position, making the development of the postal industry always at the national leading level; Secondly, the central region and the western region, the development rate of the postal industry in the central region is gradually leading the western region; The northeast region has the lowest efficiency value; The reason is that the overall economic development in the Northeast region is relatively slow, and the construction of postal infrastructure is backward, which has lowered the development speed of the national postal industry. To this end, China should tailor the appropriate industrial policies for each region, guide the flow of production factors to economically backward regions to enhance its internal development momentum, thereby narrowing the development gap between regions, and driving the overall efficiency of the postal industry's overall input and output.

(4) In 2016, each region and each province has its own resource allocation. The eastern and northeastern regions focus on the effective allocation of postal routes and fiscal expenditures. The central region pays too much attention to postal route planning and construction, while ignoring the effective allocation of postal business outlets, employees and delivery routes, resulting in poor overall input and output efficiency. The western region is superior in the allocation of human resources. The seven provinces of Shandong, Hainan, Guangxi, Shaanxi, Ningxia, Jilin and Heilongjiang have been optimized in terms of postal roads and financial expenditures, the two provinces of Inner Mongolia and Tibet were seriously affected by the total amount of postal services and the number of express shipments, which dragged down their overall input-output efficiency.

\section{Acknowledgement}

Fund Project: Zhejiang Provincial Modern Research Center for Philosophy and Social Sciences Research Center (Research on the Transformation and Upgrade Path of Port and Shipping Service Industry under the New Normal: Zhejiang Evidence) (Project No.: 16JDGH099); Xi'an University of Posts and Telecommunications Graduate Innovation Fund Key Project "Research on Technical Efficiency of China's Express Delivery Industry under Supply-side Structural Reform——Based on SFA Model Analysis” (Project No.: CXJJ2017076)

\section{References}

[1] State Post Bureau. Postal Industry Development Statistics Bulletin [EB/OL].(2018-06-04)[2018-06-09]. http://www.spb.gov.cn/sj/tjxx_1/index. html.

[2] Yang Baolin, Wang Junsheng. Comparative Analysis of Technical Efficiency Evaluation of Postal Industry in Eastern, Middle and Western Regions Based on MCMC Simulation [J]. Finance and Economics (Academic Edition), 2012(10): 32-33.

[3] Li Xiaochao, Ni Linglin, Lin Guolong. Industry Correlation and Spread Analysis of Zhejiang Postal Industry [J]. Operations Research and Management, 2016, 25(04):195-202.

[4] Jin Ruijie, Geng Kui. Analysis of Postal Investment Efficiency [J]. Journal of Beijing University of Posts and Telecommunications (Social Science Edition), 2001, 3(4): 15-19.

[5] Huang Yuansheng, Li Te, Pi Wei, et al. Research on the operational efficiency of China's postal industry based on DEA model [J]. China Science and Technology Investment, 2013 (11): 24-25+31.

[6] Wang Ling, Chen Yinzong, Fan Yu, Xu Ziwen, et al. Analysis of the Operation Mechanism and Efficiency of China's Postal Industry_B Based on the Evaluation of Two-stage DEA [J]. Journal of Beijing Jiaotong University (Social Science Edition), 2016(3): 104-113.

[7] KNEŽEVIĆ, TRUBINT N, MACURA D, et al. A Two-level approach for human resource planning towards organizational efficiency of a postal distribution system [J]. Economic Computation and Economic Cybernetics Studies and Research, 2011, 45(4):155-168. 
[8] Kiril Tochkov. The efficiency of postal services in the age of market liberalization and the internet: Evidence from Central and Eastern Europe [J]. Utilities Policy, 2015, 36.

[9] Predrag Ralević, Momčilo Dobrodolac, Dejan Marković. Using a nonparametric technique to measure the cost efficiency of postal delivery branches [J]. Central European Journal of Operations Research, 2016, 24(3).

[10] Florian Ploeckl. Uniform Service, Uniform Productivity? Regional Efficiency of the Imperial German Postal, Telegraph, and Telephone Service [J]. Australian Economic History Review, 2016, 56(2).

[11] Wei Quanling. Data Envelopment Analysis (DEA) [J]. Science Bulletin, 2000, 45 (17): 1793-1808.

[13] KAORU TONE. A slacks-based measure of efficiency in data envelopment analysis [J]. European Journal of Operational Research, 2001(3):498-509.

[14] KAORU TONE. A slacks-based measure of super-efficiency in data envelopment analysis [J]. European Journal of Operational Research, 2002(1):32-41. 